\section{Global neurosciences} masterclass: Neurocritical care Evidence to practice

\section{Ponniah Vanamoorthy}

Global Neurosciences Masterclass: Neurocritical Care - Evidence to Practice was held on $30^{\text {th }}$ November 2013 to $1^{\text {st }}$ December 2013, at "The Gateway, IT Express Way OMR, Chennai, India. It was organised by the Institute of Neurosciences and spinal disorders, Global Health City, Chennai, under the chief patronage of Dr. K. Ravindranath, Chairman and Managing Director of the Global Hospital Group, Chairmanship of Dr. K. Sridhar, Director of Neurosciences and HOD Neurosurgery, Global Health City Chennai. The organising secretary was Dr. Ponniah Vanamoorthy, Senior Consultant and In charge of Neuroanaesthesiology and Neurocritical care, Global Health City, Chennai and the Joint Secretary was Dr. Gyanesh Prakhar. The conference was endorsed by Indian Society of Neuroanaesthesiology and Critical care (ISNAAC), Neurological society of India (NSI) and Neurocritical Care Society (NCS). The theme for the conference was "Neurocritical Care: Evidence To Practice".

This conference brought together world pioneers in the field of Neurocritical care who presented their clinical experience on various critical care issues. There were

\begin{tabular}{|l|l|}
\hline \multicolumn{2}{|c|}{ Access this article online } \\
\hline Quick Response Code: & Website: \\
\hline & www.jnaccjournal.org \\
\cline { 2 - 2 } & \\
\hline
\end{tabular}

over 170 members attending the conference, and this included two international faculties and 10 international delegates. A large number of Indian experts in the field of Neurocritical care also participated in the 2-day scientific deliberations for which The Tamil Nadu Dr. MGR University awarded 20 CME credits.

A Pre-conference workshop was held on $29^{\text {th }}$ November, 2013 at the venue with four workstations:

1. Multimodal Neuro Monotoring: ICP, SjVO2, CMo2 by Dr. Virendra Jain (New Delhi), Dr. Prasanna Bidkar (Puducherry)

2. Multimodal Neuro Monotoring: EEG, TCD by Dr. Bhuvana, Rajendran (Chennai) and Dr. Lokesh B (Chennai)

3. Neuroimaging and intervention by Dr. Seena and Dr. Joy Varghese (Chennai)

4. Neurocritical Care Airway: FOB-guided intubation by Dr. Kishore (Chennai), Video Laryngoscope/ LMA by Dr. Vidya Mohanram (Chennai) and Percutaneous Dilational tracheostomy by Dr. Prakhar Gyanesh (Chennai).

It was attended by over 47 delegates who were awarded a certificate with $5 \mathrm{CME}$ credits by The Tamil Nadu Dr. MGR Medical University, Chennai.

The first day, the conference began after a brief formal opening by Prof. H. H. Dash, New Delhi, followed by the first session of the day "Prognostic Indicators in neurocritical care" by Dr. Ramesh VJ (Bangalore), "Targeted temperature Management" by Dr. Nidhi Panda (Chandigarh), and Sedation and Analgesia in Neurocritical care by Dr. Anil Parakh (Mumbai). This session was chaired by Dr. Vidya Mohanram, Dr. Illan Kumaran and Dr. Subramaniam. Second session of the day included nutrition in Neurocritical care by Dr. Amna Goswami (Kolkata), Postoperative Neurocritical care by Dr. Shashi Srivastav (Lucknow) and Sedation and Extubation failure by Dr. Thamarai Selvi (Chennai). This session was chaired by Dr. K Bhanu, Dr. Roopesh Kumar and Dr. Madhan Kumar.

After a short tea break, inaugural function by lighting the lamp was held. Prof. S Kalyana Raman and Prof. Arjundas were the dignitaries. This was followed by third session of the day which included refractory status

Department of Neuroanesthesiology and Neuro Critical Care, Institute of Neurosciences and Spinal Disorders, Global Health City, Chennai, Tamil Nadu, India

Address for correspondence:

Dr. Ponniah Vanamoorthy, Department of Neuroanesthesiology and Neuro Critical Care, Institute of Neurosciences and Spinal Disorders, Global Health City, \#439, Cheran Nagar, Perumbakkam, Chennai - 600 100, Tamil Nadu, India. E-mail: drponns@gmail.com 
by Dr. Ramesh VJ (Bangalore), Status in children: New guidelines by Dr. Murugan (Chennai), Plasmapheresis by Dr. Rema Menon (Chennai) and Cerebral resuscitation by Dr. Ponniah (Chennai).

The hallmark of the first day programme was panel discussion on "How would I do it?" after a sumptuous lunch. With the eminent panellists like Dr. Radha Krishnan (Bangalore), Dr. Ravi Kumar (Chennai), Dr. Suresh Kumar (Chennai), Dr. Rajshri Deopujari (Chennai), Dr. Ranganathan Jothi (Chennai) and Dr. Naveen (Hyderabad). The various case scenarios were presented by Dr. Joy Varghese, Dr. Halprasanth and Dr. Prakhar Gyanesh. The panel discussion was moderated by Dr. K Shridhar and Dr. V Ponniah.

The fifth session of the day started with a talk on Value of ICP Monitoring in TBI by Dr. CE Deo Pujari (Mumbai), Neuroprotection in Traumatic Brain Injury by Dr. H H Dash (New Delhi), ICP in TBI: Maximal Medical management by Dr. Radhakrishnan (Bangalore) and Osmotic therapy: Practice update by Dr. Mathew Joseph of CMC, Vellore.

The day concluded with the sixth session with topics “TBI: Time for New Guidelines?" by Dr. Prasanna Bidkar (Jipmer), "Decompressive craniectomy: Current update" by Dr. Sridhar (Chennai)", "Cervical Spine Injury: Recognition is the key" by Dr. S S Kumar (Chennai) and "Methylprednisolone: is there a role in ASCI ?" by Dr. U Shrinivasan (Chennai).

The day ended with a banquet gala dinner at the gateway IT Expressway which included live DJ and participants had a gala time shaking their legs to the tunes.

Second day started with Session 7 with topics "Sonology in
Neurocritical care" by Dr. Lokesh (Chennai), Spontaneous ICH an update by Dr. JMK Murthy (Hyderabad) and "Intensive care management of Vasospasm after aSAH" by Dr. M P Pandia (New Delhi). Session 8 of the day had three lectures "Acute Stroke: IV Thrombolysis and beyond "by Dr. Joy Varghese (Chennai), "Ultra early rehabilitation in Stroke patients" by Dr. DS Halprashanth (Chennai) and "Storm before the calm: Paroxysmal Autonomic Instability after Brain injury" by Dr. P K Bithal (New Delhi). In the consequent session which was chaired by Dr. Amna Goswami and Dr. P K Bithal, Dr. K Sridhar, Dr. V Ponniah and Dr. H H Dash emphasised on the need of Neurocritical Care an Emerging Subspecialty which should include neuroanaesthesiologist, neurophysicians and neurosurgeons and specially trained ancillary specialists.

Session 10 included "Non-neurological organ dysfunction" by Dr. Virendra Jain (New Delhi), "Brain Death" by Dr. Lakshminarasimhan (Chennai) and "Difficult weaning in neurologically ill" by Dr. Srilatha (Hyderabad).

The conference ended with a brainstorming panel discussion with eminent panellists Dr. Rajasekhar (New Delhi), Dr. Ravisankar (Chennai), Dr. Dash (New Delhi) and Dr. Nigel Symss (Chennai) on the Ethical and Legal issues in Neurocritical Care.

The organising chairman and secretary thanked the delegates for their active participation during the conference. The conference ended with cheers and applause for the hosts from the audience led by Dr. Amna Goswami followed by photo session and lunch.

Following the conference was a 4 hours Neurocritical care Nursing CNE which was attended by 75 critical care-registered nurses. 